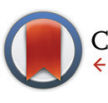

CrossMark \& click for updates

Cite this: Polym. Chem., 2016, 7, 3165

Received 3rd March 2016, Accepted 11th April 2016

DOI: $10.1039 / \mathrm{c} 6$ py00381h

www.rsc.org/polymers

\title{
Structural effects of dibromocarbazoles on direct arylation polycondensation with 3,4-ethylenedioxythiophene $\dagger$
}

\begin{abstract}
Wei Li and Tsuyoshi Michinobu*
The direct arylation reaction of a $\mathrm{C}-\mathrm{H}$ bond with aromatic halides has been employed as a novel environmentally-friendly polymerization method for producing conjugated polymers. In this article, 3,4-ethylenedioxythiophene (EDOT) was copolymerized with a series of dibromocarbazoles (Cbzs) by the phosphine-free and microwave-assisted direct arylation polycondensation. The microwave heating dramatically shortened the reaction time compared to conventional heating. Under optimal conditions, a solution processable linear polymer, 3,6-Cbz-EDOT, with the number-average molecular weight $\left(M_{n}\right)$ of 5600 and polydispersity index $\left(M_{w} / M_{n}\right)$ of 1.9 was successfully synthesized. In contrast, the other dibromocarbazole monomers with different substitution patterns, i.e., 2,7-Cbz and 1,8-Cbz, did not afford the corresponding soluble linear polymers due to the occurrence of undesired crosslinking and the poor reactivity caused by steric hindrance or unsuitable catalysts, respectively. The electrochromic properties of 3,6-Cbz-EDOT were investigated. The thin polymer film displayed two-step color changes with the increasing potentials. The first color change was highly reversible with the switching times of the coloring and bleaching processes being 3.2 and 2.0 s, respectively.
\end{abstract}

\section{Introduction}

Carbazole-based conjugated polymers have attracted much attention due to their excellent optical, electrochemical, and conducting properties, which can be controlled by the connectivity patterns of the carbazole unit and comonomer structures. $^{1-8}$ The initially developed conjugated carbazole polymers were poly(3,6-carbazole) derivatives because the 3,6positions of the carbazole showed the highest reactivity for oxidative polymerization as well as towards various electrophiles. ${ }^{9}$ In 2001, Leclerc et al. and Müllen et al. independently reported the efficient synthesis of the 2,7-dihalogeno-carbazole derivatives. ${ }^{10,11}$ Their pioneering studies opened the door to a new class of poly(2,7-carbazole) derivatives, which served as a chemically stable alternative of blue-emitting polyfluorene derivatives. ${ }^{12}$ In addition to the emissive properties, excellent p-type semiconducting properties were demonstrated in bulkheterojunction organic solar cells, thin film transistors, thermoelectric and electrical memory devices when donor-acceptor alternating poly(2,7-carbazole)s were designed. ${ }^{13-19}$ In contrast, our group has successfully developed poly(1,8-carba-

Department of Organic and Polymeric Materials, Tokyo Institute of Technology, 2-12-1 Ookayama, Meguro-ku, Tokyo 152-8552, Japan.

E-mail: michinobu.t.aa@m.titech.ac.jp

$\dagger$ Electronic supplementary information (ESI) available: Monomer synthesis, NMR characterization, and thermal analyses. See DOI: 10.1039/c6py00381h zole) derivatives by the stepwise functionalization of the monomeric carbazole unit. ${ }^{20,21}$ The poly(1,8-carbazole)s displayed the combined properties of the poly(3,6-carbazole)s in terms of the connectivity pattern and poly(2,7-carbazole)s in terms of the effective conjugation length evaluated on the basis of the longest absorption maxima $\left(\lambda_{\max }\right) .^{22-24}$

The conventional synthesis of the aforementioned conjugated carbazole polymers was based on the Pd-catalyzed polycondensation, such as the Suzuki, Stille, and Sonogashira polycondensations. However, in order to construct an environmentally benign and cost-effective synthetic route of conjugated polymers, the direct arylation protocol, which activates the $\mathrm{C}-\mathrm{H}$ bonds of the unprepared arenes or heteroarenes to directly react with aryl halides, was recently introduced. ${ }^{25-27}$ In contrast to the necessity of the multistep tedious preparation of bifunctional boronic acids (for Suzuki coupling) and tin compounds (for Stille coupling), the direct arylation protocol can reduce the synthetic steps and, more importantly, does not produce a stoichiometric amount of toxic byproducts. Therefore, the number of publications using this protocol is currently increasing. Some of the most frequently used $\mathrm{C}-\mathrm{H}$ activated reactants or bifunctional monomers are the thiophene-based substances. For example, 3,4-dimethylthiophene and 3,4-ethylenedioxythiophene (EDOT) possess activated $\mathrm{C}-\mathrm{H}$ bonds only at the 2- and 5-positions of the thiophene ring, and accordingly, they can serve as a bifunctional monomer for the direct arylation polycondensation. ${ }^{28-32}$ Kanbara and his 
coworkers recently succeeded in optimizing the polycondensation of such monomers using $\mathrm{Pd}(\mathrm{OAc})_{2}$ but without any phosphine ligands. ${ }^{33}$ Furthermore, they demonstrated the effectiveness of microwave heating in order to increase the monomer reactivities and obtain high molecular weight polymers. ${ }^{34}$ It is indeed widely recognized that the microwaveassisted direct arylation polycondensation is an efficient process for synthesizing optoelectronic organic polymers. ${ }^{35-37}$

We now describe the structural effects of the dibromocarbazole monomers on the microwave-assisted direct arylation polycondensation with EDOT. We show that 3,6-dibromocarbazole is the most suitable for producing linear soluble polymers as compared to the 2,7- and 1,8-dibromocarbazole counter structures. We also demonstrate the reversible electrochromic properties of the resulting polymer based on 3,6-carbazole and EDOT. Overall, the results reported here indicate the important aspects of the monomer structures and polymer properties regarding the emerging polymerization technique of direct arylation polycondensation.

\section{Experimental}

\section{Materials}

3,6-Dibromo-9-(2-ethylhexyl)carbazole $\quad$ 1, ${ }^{38}$ 2,7-dibromo-9-(2ethylhexyl)carbazole $2,{ }^{11}$ and 3,6-di-tert-butylcarbazole ${ }^{20}$ were prepared according to the reported literature procedure. Commercially available solvents and reagents were used without further purification unless stated otherwise.

\section{General methods}

${ }^{1} \mathrm{H}$ NMR and ${ }^{13} \mathrm{C}$ NMR spectra were measured on a JEOL model AL300 spectrometer at $20{ }^{\circ} \mathrm{C}$. Chemical shifts are reported in ppm downfield from $\mathrm{SiMe}_{4}$, using the solvent's residual signal as an internal reference. Fourier transform infrared (FT-IR) spectra were recorded on a JASCO FT/IR-4100 spectrometer in the range from 4000 to $600 \mathrm{~cm}^{-1}$. MALDI-TOF mass spectra were measured on a Shimadzu/Kratos AXIMA-CFR mass spectrometer equipped with nitrogen laser $(\lambda=337 \mathrm{~nm})$ and pulsed ion extraction, which was operated in a linear-positive ion mode at an accelerating potential of $20 \mathrm{kV}$. Dichloromethane solutions containing $1 \mathrm{~g} \mathrm{~L}^{-1}$ of a sample, $10 \mathrm{~g} \mathrm{~L}^{-1}$ of dithranol, and $1 \mathrm{~g} \mathrm{~L}^{-1}$ of sodium trifluoroacetate were mixed at the ratio of $1: 1: 1$, and $1 \mathrm{~mL}$ aliquot of this mixture was deposited onto a sample target plate. Gel permeation chromatography (GPC) was measured on a JASCO GULLIVER 1500 equipped with a pump (PU-2080 Plus), an absorbance detector (RI-2031 Plus), and two Shodex GPC KF-803 columns (8.0 mm I.D. $\times 300 \mathrm{~mm} \mathrm{~L}$ ) based on a conventional calibration curve using polystyrene standards. Tetrahydrofuran $\left(40{ }^{\circ} \mathrm{C}\right)$ was used as a carrier solvent at the flow

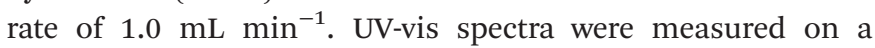
JASCO V-670 spectrophotometer. Fluorescence spectra were measured on a JASCO FP6500 spectrophotometer. Thermogravimetric analysis (TGA) and differential scanning calorimetry (DSC) were carried out on a Rigaku Thermoplus TG8120 and DSC8230, respectively, under flowing nitrogen at the scan rate of $10{ }^{\circ} \mathrm{C} \mathrm{min}^{-1}$. Electrochemistry measurements were carried out on a BAS electrochemical analyzer model $612 \mathrm{C}$ at $25{ }^{\circ} \mathrm{C}$ in dehydrated $\mathrm{CH}_{3} \mathrm{CN}$ containing $0.1 \mathrm{M}\left(n \mathrm{C}_{4} \mathrm{H}_{9}\right)_{4} \mathrm{NPF}_{6}$ in the three electrode cell. The working, reference, and auxiliary electrodes were an indium-tin-oxide (ITO) electrode, $\mathrm{Ag} / \mathrm{Ag}^{+} /$ $\mathrm{CH}_{3} \mathrm{CN} /\left(n \mathrm{C}_{4} \mathrm{H}_{9}\right)_{4} \mathrm{NPF}_{6}$, and a Pt wire, respectively. Ferrocene/ ferrocinium $\left(\mathrm{Fc} / \mathrm{Fc}^{+}\right)$couple was $0.13 \mathrm{~V}\left(v s . \mathrm{Ag} / \mathrm{Ag}^{+}\right)$. All potentials are referenced to the $\mathrm{Ag} / \mathrm{Ag}^{+}$couple unless otherwise stated. Polymer thin films were prepared on an ITO electrode (10 $\Omega$, about $0.8 \times 2.5 \mathrm{~cm}^{2}$ ) by spray-coating of polymer solutions $\left(5.0 \mathrm{~g} \mathrm{~L}^{-1}\right.$ in $\mathrm{CH}_{2} \mathrm{Cl}_{2}$ ). Absorption spectra of spectroelectrochemistry experiments were measured on an Agilent 8453 UV-vis spectrophotometer.

\section{General procedure for direct arylation polycondensation}

Dibromocarbazole monomer $(0.5 \mathrm{mmol})$ and 3,4-ethylenedioxythiophene (EDOT, $0.5 \mathrm{mmol}$ ) were placed on a reaction tube. The tube was transferred into a glove box under argon atmosphere. Then, $1.0 \mathrm{~mol} \%$ of $\mathrm{Pd}(\mathrm{OAc})_{2}, 1.5$ equiv. of potassium pivalate (KOPiv), and dry $\mathrm{N}, \mathrm{N}$-dimethylacetamide (DMAc, $2.5 \mathrm{~mL}$ ) were added. The tube was sealed, removed from the glove box, and subjected to the microwave synthesis. After the reaction was completed, it was cooled to room temperature and the resulting product was washed with water, methanol, and hexane. The solid product was dissolved into chloroform and reprecipitated into methanol.

3,6-Cbz-EDOT: $87 \%$ yield. ${ }^{1} \mathrm{H}$ NMR (300 MHz, $\left.\mathrm{CDCL}_{3}\right): \delta$ $8.47(\mathrm{~s}, 2 \mathrm{H}), 7.91(\mathrm{~s}, 2 \mathrm{H}), 7.26(\mathrm{~s}, 2 \mathrm{H}), 4.39(\mathrm{~s}, 4 \mathrm{H}), 4.10(\mathrm{~d}, J=$ $4.2 \mathrm{~Hz}, 2 \mathrm{H}), 2.00(\mathrm{~s}, 1 \mathrm{H}), 1.26$ (d, $J=4.5 \mathrm{~Hz}, 8 \mathrm{H}), 0.85 \mathrm{ppm}(\mathrm{s}$, $6 \mathrm{H})$. IR (neat): $\nu=2923,2857,1596,1514,1432,1359,1292$, 1213, 1149, 1090, 1034, 915, 865, 802, 734, $632 \mathrm{~cm}^{-1}$.

\section{Results and discussion}

\section{Polymer synthesis}

Three symmetric dibromocarbazole monomers with different substitution patterns, 1-3, were prepared (ESI $\dagger$ ). A branched ethylhexyl group was introduced into the 9-position of the carbazole in order to increase the solubility of the resulting polymers. The dibromocarbazole monomers were copolymerized with 3,4-ethylenedioxythiophene (EDOT) under direct arylation conditions using $\mathrm{Pd}(\mathrm{OAc})_{2}$ as a catalyst and potassium pivalate (KOPiv) as a base in $N, N$-dimethylacetamide (DMAc) (Scheme 1). First, the reactivity of 3,6-dibromocarbazole 1 was investigated (Table 1). The direct arylation polycondensation of 1 and EDOT at $100{ }^{\circ} \mathrm{C}$ for $6 \mathrm{~h}$ produced the corresponding polymer, 3,6-Cbz-EDOT, with the number-average molecular weight $\left(M_{\mathrm{n}}\right)$ of 3000 and polydispersity index $\left(M_{\mathrm{w}} / M_{\mathrm{n}}\right)$ of $1.6 \mathrm{in}$ $72 \%$ yield (run 6 in Table 1). It should be noted that the employed conditions were comparable to or even better than other reported conditions with different catalyst/ligand combinations, such as $\mathrm{Pd}(\mathrm{OAc})_{2} / \mathrm{PCy}_{3} \cdot \mathrm{HBF}_{4}{ }^{39}$ and $\mathrm{Pd}_{2}(\mathrm{dba})_{3} /$ $\mathrm{P}(o-\mathrm{MePh})_{3}{ }^{40}$ (Table $\left.\mathrm{S} 1 \dagger\right)$. In order to increase the molecular weights, microwave synthesis was adopted due to its high 

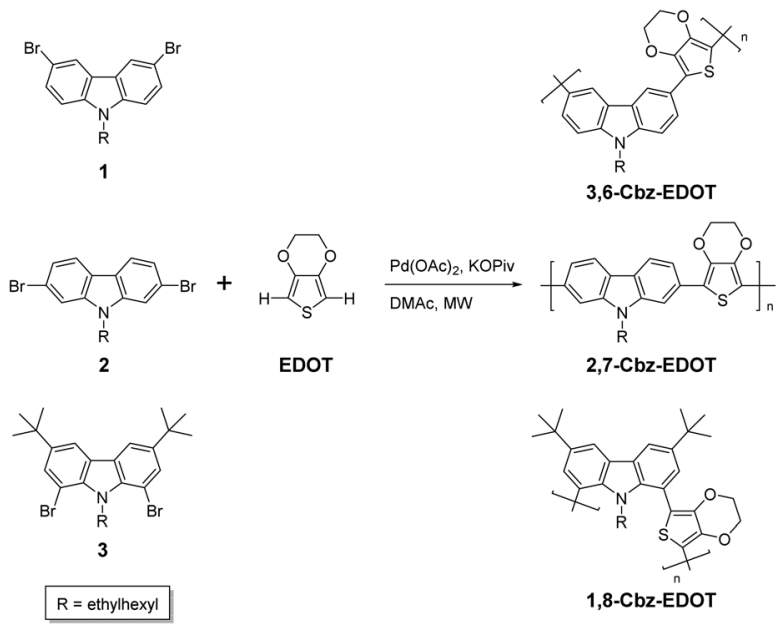

2,7-Cbz-EDOT

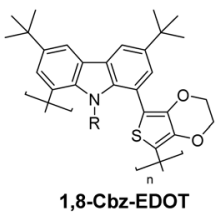

Scheme 1 Polycondensation of EDOT with various dibromocarbazole comonomers.

Table 1 Direct arylation polycondensation of 1 and EDOT ${ }^{a}$

\begin{tabular}{lccclc}
\hline Run & Temp. $\left({ }^{\circ} \mathrm{C}\right)$ & Time $(\mathrm{min})$ & $M_{\mathrm{n}}{ }^{b}\left(\mathrm{~g} \mathrm{~mol}^{-1}\right)$ & $M_{\mathrm{w}} / M_{\mathrm{n}}{ }^{b}$ & Yield (\%) \\
\hline 1 & 60 & 30 & 600 & 2.4 & 14 \\
2 & 80 & 30 & 5600 & 1.9 & 87 \\
3 & 80 & 60 & 2500 & 1.6 & 56 \\
4 & 100 & 30 & 4100 & 1.7 & 68 \\
5 & 100 & 60 & 5000 & 2.1 & 75 \\
$6^{c}$ & 100 & 360 & 3000 & 1.6 & 72 \\
7 & 120 & 30 & 1700 & 1.4 & 45
\end{tabular}

${ }^{a}$ Performed in the presence of $1.0 \mathrm{wt} \% \mathrm{Pd}(\mathrm{OAc})_{2}$ and 1.5 equiv. KOPiv in DMAc under microwave irradiation. ${ }^{b}$ Determined by GPC (THF eluent, calibrated by polystyrene standards). ${ }^{c}$ Regular heating.

efficiency, short reaction time, and ready accessibility. Based on the temperature dependence for the constant polymerization time of $30 \mathrm{~min}$ (runs 1, 2, 4, and 7 in Table 1), it was found that $80{ }^{\circ} \mathrm{C}$ was the most suitable temperature for producing the highest $M_{\mathrm{n}}$ of 5600. In order to further increase the $M_{\mathrm{n}}$, the polymerization time was increased to $60 \mathrm{~min}$ (run 3 in Table 1). However, this change resulted in a decrease in the $M_{\mathrm{n}}$ to 2500. Similar to this result, there was an optimum polymerization time at $100{ }^{\circ} \mathrm{C}$. A prolonged polymerization time from 30 to $60 \mathrm{~min}$ led to a slight increase in the $M_{\mathrm{n}}$ from 4100 to 5000 (runs 4 and 5 in Table 1). All the polymerization conditions produced the desired 3,6-Cbz-EDOT with a reasonable polydispersity in moderate yields except for the polymerization at $60{ }^{\circ} \mathrm{C}$ for $30 \mathrm{~min}$ (run 1 in Table 1 ).

The chemical structure of 3,6-Cbz-EDOT was confirmed by its ${ }^{1} \mathrm{H}$ NMR and IR spectra. In the ${ }^{1} \mathrm{H}$ NMR spectrum, the aromatic peaks were ascribed to the 3,6-carbazole unit. In addition, the methylene group directly attached to the nitrogen atom of the carbazole and the ethylene groups of EDOT were detected at 4.39 and $4.21 \mathrm{ppm}$, respectively (Fig. 1). In the IR spectrum, the peak at $890 \mathrm{~cm}^{-1}$ attributed to the $\mathrm{C}-\mathrm{H}$ bending of EDOT disappeared, suggesting the polymer formation. The thermal properties of the 3,6-Cbz-EDOT were measured by

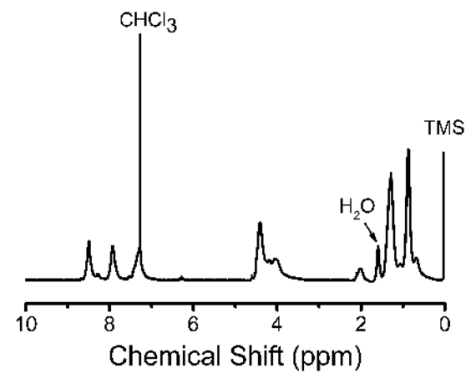

Fig. $1{ }^{1} \mathrm{H}$ NMR of $3,6-\mathrm{Cbz}-\mathrm{EDOT}$ in $\mathrm{CDCl}_{3}$.

thermogravimetric analysis (TGA) and differential scanning calorimetry (DSC). The TGA showed that the 5\% weight loss temperature $\left(T_{\mathrm{d} 5 \%}\right)$ of 3,6-Cbz-EDOT was $386{ }^{\circ} \mathrm{C}$, indicating a high thermal stability (Fig. S7†). The DSC curve did not reveal clear melting and crystallization peaks, but it exhibited a weak endothermic transition at $148{ }^{\circ} \mathrm{C}$ upon heating and an exothermic one at $111^{\circ} \mathrm{C}$ upon cooling, attributable to a glass transition (Fig. $\mathrm{S} 8 \dagger$ ).

With the success of 3,6-Cbz-EDOT in mind, other dibromocarbazole monomers with different substitution patterns, namely the 2,7-dibromocarbazole and 1,8-dibromocarbazole derivatives, 2 and 3 , were also subjected to the microwaveassisted direct arylation polycondensation with EDOT under the same conditions (Scheme 1). Surprisingly, the polymerization of 2 and EDOT produced insoluble gels even when the lower temperature of $60{ }^{\circ} \mathrm{C}$ and shorter time of $30 \mathrm{~min}$ were adopted. This result suggested that the $\mathrm{C}-\mathrm{H}$ activation most likely occurred at the 3,6-positions of 2 in addition to the planned direct arylation coupling at the 2,7-positions, resulting in the cross-linking reactions. Also, this was not caused by the solubility problem of the resulting polymer, because another 2,7-dibromocarbazole monomer 4 with a longer branched alkyl chain (2-hexyldecyl group) gave the same result when polymerized under the microwave-assisted direct arylation conditions. It should be noted that the 3,6-positions of the carbazole derivatives are active $\mathrm{C}-\mathrm{H}$ units in the direct arylation coupling. ${ }^{41}$ Accordingly, the gels composed of $2,7-\mathrm{Cbz}^{-}$ EDOT were not further characterized due to the insolubility in common organic solvents, such as chloroform, dichloromethane, THF, and DMSO. In contrast, the direct arylation polycondensation of 3 and EDOT did not proceed very well under the employed conditions. This might be due to the steric hindrance of the 1,8-positions mainly caused by the bulky ethylhexyl group at the adjacent 9-position or unsuitable catalysts for this substance. ${ }^{42}$ In addition, the 3,6-positions of 3 were perfectly blocked by the tert-butyl group, thereby preventing self-polycondensation.

\section{Optical and electrochemical properties}

The UV-vis absorption and fluorescence spectra of 3,6-CbzEDOT were measured in $\mathrm{CH}_{2} \mathrm{Cl}_{2}$ and in a thin film (spincoated on an ITO glass). We recently reported that the effective conjugation length of the $3,6-\mathrm{Cbz}$ units saturates at the penta- 
mer. ${ }^{43}$ Hence, it was postulated that the 3,6-Cbz-EDOT with the $M_{\mathrm{n}}$ of 5600 (14 repeat units) sufficiently shows the polymer properties. The absorption maximum $\left(\lambda_{\max }\right)$ in $\mathrm{CH}_{2} \mathrm{Cl}_{2}$ was $354 \mathrm{~nm}$, while the $\lambda_{\max }$ of the thin film bathochromically shifted to $374 \mathrm{~nm}$ (Fig. 2). This red shift was due to the strong intermolecular interaction and the closer packing of the polymer backbones in the thin film. The fluorescence spectra of 3,6-Cbz-EDOT exhibited two emission bands at 438 and $469 \mathrm{~nm}$ in $\mathrm{CH}_{2} \mathrm{Cl}_{2}$ and 486 and $514 \mathrm{~nm}$ in the thin film. The red shift in the fluorescence spectra was more significant than that in the absorption spectra. Thus, the difference in the emission colors between the blue in solutions and green in films could be visually distinguished (Fig. S9†).

The cyclic voltammetry (CV) of 3,6-Cbz-EDOT was measured in $\mathrm{CH}_{3} \mathrm{CN}$ with $0.1 \mathrm{M}\left(n \mathrm{C}_{4} \mathrm{H}_{9}\right)_{4} \mathrm{NPF}_{6}$ as the supporting electrolyte at $20{ }^{\circ} \mathrm{C}$ (Fig. 3). The film showed a reversible multistep oxidation due to the highly electron-rich carbazole and EDOT units as well as the electroactive connectivity position of the 3,6-carbazoles. ${ }^{44-47}$ In order to determine the exact oxidation potentials, differential pulse voltammetry (DPV) was measured using the same setup. The DPV revealed three oxidation peaks

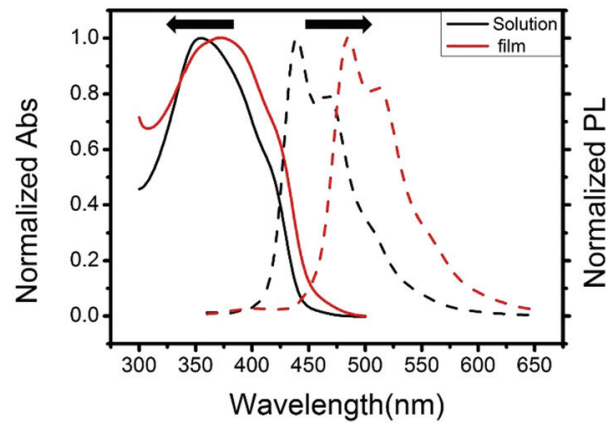

Fig. 2 Normalized UV-vis absorption and fluorescence spectra of 3,6Cbz-EDOT in $\mathrm{CH}_{2} \mathrm{Cl}_{2}$ measured at $10^{-6} \mathrm{M}$ repeat unit ${ }^{-1}$ and in thin films.

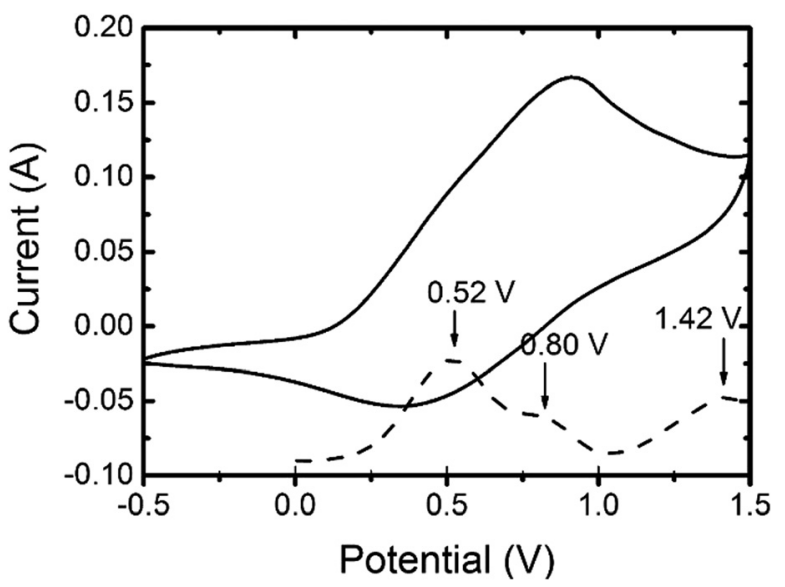

Fig. 3 Cyclic voltammetry (solid line) and differential pulse voltammetry (dotted line) of 3,6-Cbz-EDOT films on an ITO electrode, measured in $\mathrm{CH}_{3} \mathrm{CN}$ with $0.1 \mathrm{M}\left(n \mathrm{C}_{4} \mathrm{H}_{9}\right)_{4} \mathrm{NPF}_{6}$ at the scan rate of $0.1 \mathrm{~V} \mathrm{~s}^{-1}$ under flowing nitrogen.

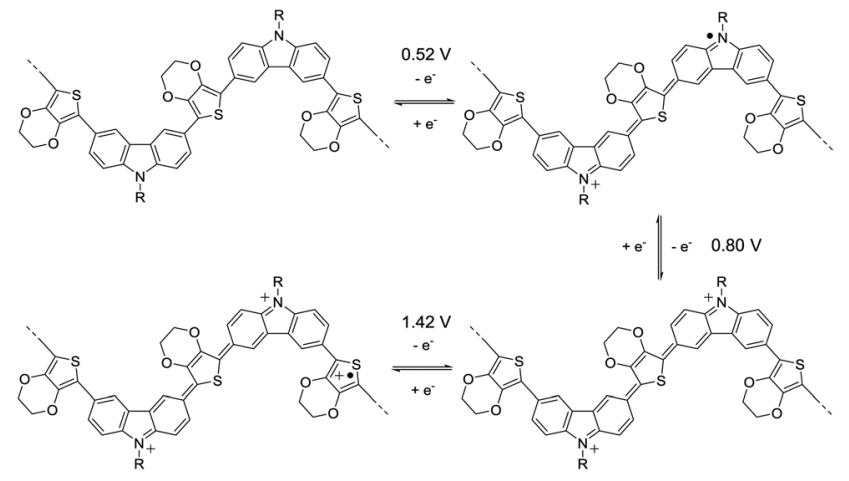

Scheme 2 Schematic illustration of the stepwise oxidation of 3,6-CbzEDOT.

at $0.52,0.80$, and $1.42 \mathrm{~V}\left(v s . \mathrm{Ag} / \mathrm{Ag}^{+}\right)$. This result suggests the stepwise generation of three different charge states in the oligomeric repeat units, namely a cation radical, bication, and trication radical as illustrated in Scheme 2. Similar to the emeraldine base of polyaniline, the positive charges are formally located at the carbazole nitrogens up to the second oxidation steps. However, the third oxidation occurs at the neutral EDOT moieties.

\section{Electrochromism}

Based on the optical and electrochemical studies, the electrochromic properties of the 3,6-Cbz-EDOT thin film were investigated. Spectroelectrochemistry was used to monitor the spectral changes in the electrochromic films. The spray-coated thin films on an ITO-coated glass plate together with the reference and counter electrodes were placed in a 1-cm cuvette. The UV-vis-near infrared spectra were measured in $\mathrm{CH}_{3} \mathrm{CN}$ containing $0.1 \mathrm{M}\left(n \mathrm{C}_{4} \mathrm{H}_{9}\right)_{4} \mathrm{NPF}_{6}$ at $20{ }^{\circ} \mathrm{C}$. The polymer films displayed three distinct colors in response to the application of different potentials. When potentials more positive than $0.50 \mathrm{~V}$ were applied to the film, the original absorption band at $356 \mathrm{~nm}$ started to decrease and a new absorption band at $519 \mathrm{~nm}$ appeared (Fig. 4). This spectral change continued up to the potential application of $0.80 \mathrm{~V}$. As a result of this electro-

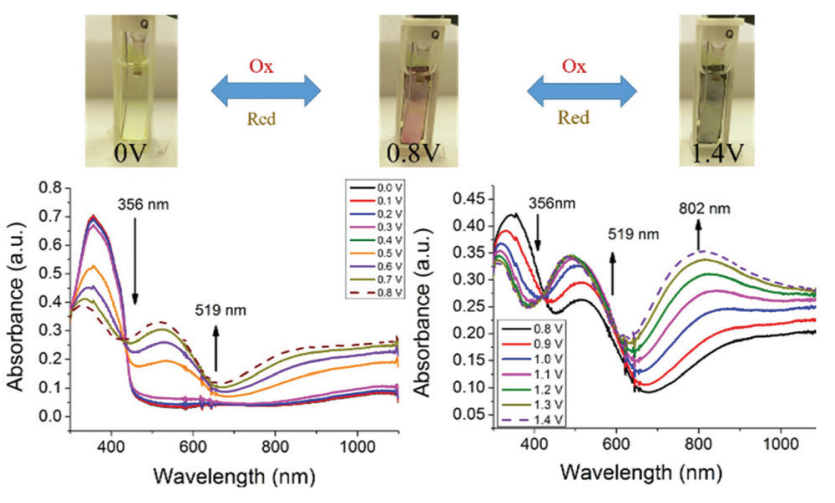

Fig. 4 Spectroelectrochemistry of 3,6-Cbz-EDOT films on an ITO electrode measured in $\mathrm{CH}_{3} \mathrm{CN}$ with $0.1 \mathrm{M}\left(n \mathrm{C}_{4} \mathrm{H}_{9}\right)_{4} \mathrm{NPF}_{6}$. 
chromism, the pale yellow color of the neutral polymer film changed to red. However, during the course of the continuous spectral changes up to $0.80 \mathrm{~V}$, there were two isosbestic points at $443 \mathrm{~nm}(0.00-0.50 \mathrm{~V})$ and $431 \mathrm{~nm}(0.50-0.80 \mathrm{~V})$ (Fig. S10 $\dagger)$. The first isosbestic point corresponds to the generation of cation radicals from the neutral state, and the formed cation radical species smoothly changed into the closed-shell structure of bication during the spectral changes with the second isosbestic point. Accordingly, the stable red color of the film is attributed to the bication. A further continuous increase in the applied potential from 0.80 to $1.40 \mathrm{~V}$ resulted in a well-defined low-energy band at $802 \mathrm{~nm}$ ascribed to the trication radical state. Thus, the film color eventually turned dark blue. It was thought that this state is the full oxidation form of the polymer main chain of which the chemical stability is slightly beyond the limit (vide infra).

Reversible color production by controlled potential applications is essential for the fabrication of practical electrochromic and electrofluorochromic devices. ${ }^{48-53}$ To gain a detailed insight into the film stability and coloring mechanism, the response time and switching processes were investigated. The original absorbance at $356 \mathrm{~nm}$ and the bication absorbance at $519 \mathrm{~nm}$ were monitored as a function of time (Fig. 5a). The pulse time was determined to be $20 \mathrm{~s}$. The UV-vis-near infrared spectral changes in the oxidation process from the neutral to carbazole bication were fully reversible. The switching time
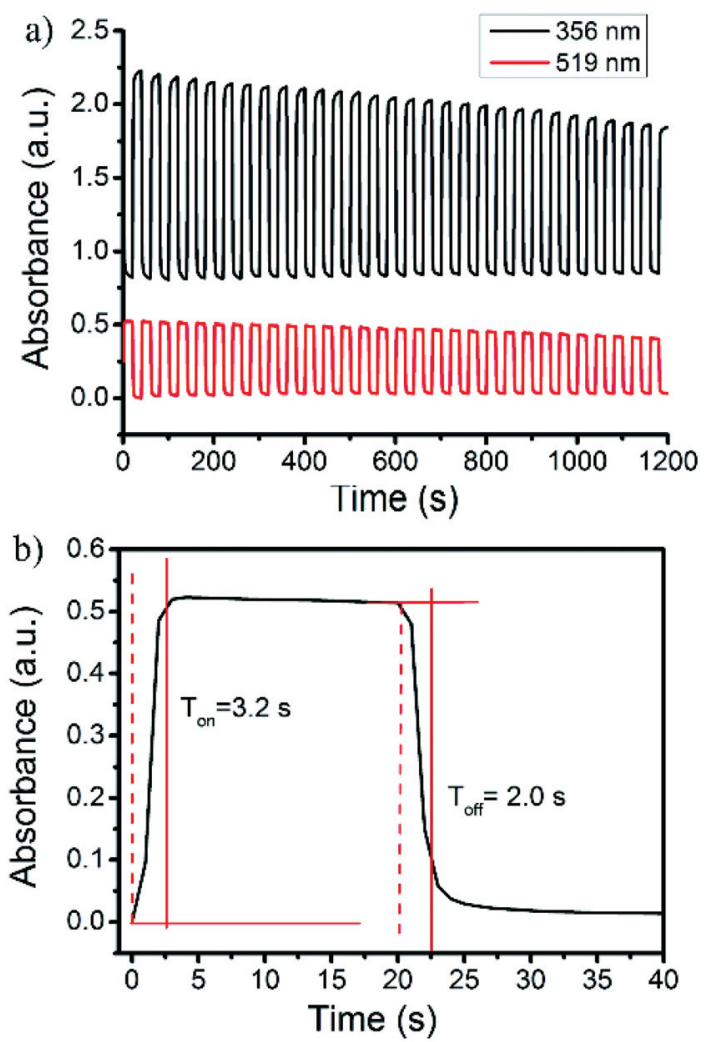

Fig. 5 (a) Repeated absorbance changes at $356 \mathrm{~nm}$ and $519 \mathrm{~nm}$ and (b) enlarged change at $356 \mathrm{~nm}$ upon electrochromic switching between 0 and $0.8 \mathrm{~V}$ of the $3,6-\mathrm{Cbz}-$ EDOT film on the ITO-coated glass plate. was evaluated as $90 \%$ of the full switch, because it was difficult to visually perceive any further color changes beyond this point. The results revealed that the switching times of the coloring and bleaching process for the polymer film were 3.2 and $2.0 \mathrm{~s}$, respectively (Fig. 5b). The polymer film quickly switched between the neutral yellow and oxidized red states. Unfortunately, the second electrochromic color change of the 3,6-Cbz-EDOT film from red to dark blue was not fully reversible upon the repeated pulse applications. This was probably due to the unstable trication radical state of the fully oxidized polymer backbone (vide supra).

The proportionality factor that relates the optical absorbance change of an electrochrome at a given wavelength $(\Delta A)$ to the density of the injected/ejected electrochemical charge necessary to induce a full switch $\left(Q_{\mathrm{d}}\right)$ is called the coloration efficiency (CE). CE values are inherent to the electrochromic material under characterization, some being intensely colored by nature in at least one redox state which others display fainter tones over their doping/dedoping cycles regardless of the deposited film thicknesses. The quantitative determination of the CE was estimated using the following equation:

$$
\mathrm{CE}=\Delta A / Q_{\mathrm{d}}
$$

where $Q_{\mathrm{d}}$ is in $\mathrm{C} \mathrm{cm}^{-2}$ and $\mathrm{CE}$ is in $\mathrm{cm}^{2} \mathrm{C}^{-1}$. For the electrochromic device based on 3,6-Cbz-EDOT, the CE was calculated
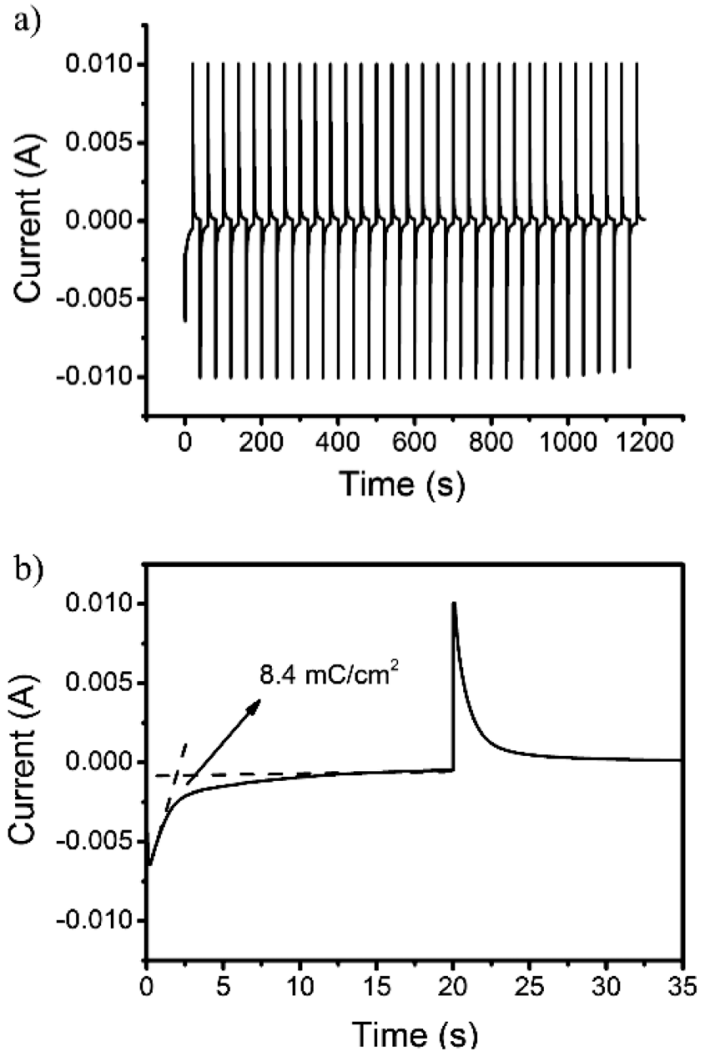

Fig. 6 Current consumption upon (a) repeated and (b) enlarged electrochromic switching between 0 and $0.8 \mathrm{~V}$ of the $3,6-\mathrm{Cbz}$-EDOT on the ITO-coated glass plate. 
to be $61.9 \mathrm{~cm}^{2} \mathrm{C}^{-1}$ (Fig. 6). This value is comparable to that reported for aromatic polyamines. ${ }^{54,55}$

\section{Conclusions}

In summary, the microwave-assisted direct arylation polymerization of dibromocarbazole derivatives and EDOT was investigated. A short polymerization time was the prominent feature of the microwave heating. Only the 3,6-dibromocarbazole derivative afforded the corresponding soluble polymer, 3,6-Cbz-EDOT, whereas the other counter dibromocarbazole monomers produced insoluble gels (2,7-dibromocarbazole) and oligomers (1,8-dibromocarbazole). The electrochromic application of 3,6-Cbz-EDOT was investigated based on the electroactive structure of the 3,6-carbazole-based polymers. The 3,6-Cbz-EDOT films showed two-step color changes from light-yellow to red and finally to dark blue under a continuous potential increase. The detailed analysis of the electrochromic behavior revealed that the first step was fully reversible with the fast response time of $2.0 \mathrm{~s}$ and the coloration efficiency of $61.9 \mathrm{~cm}^{2} \mathrm{C}^{-1}$. This is the first report that demonstrates the advantageous features of the 3,6-dibromocarbazole monomer over the other symmetric dibromocarbazole monomers in the microwave-assisted direct arylation polymerization. In addition, it was clearly shown that the resulting 3,6-Cbz-EDOT is a very promising electrochromic polymer.

\section{Acknowledgements}

This work was supported by JSPS KAKENHI Grant Number 26620173, Kurata Memorial Hitachi Science and Technology Foundation, Tokuyama Science Foundation, TOBE MAKI Scholarship Foundation, Maekawa Houonkai Foundation, and the Support for Tokyotech Advanced Researchers (STAR).

\section{Notes and references}

1 J. V. Grazulevicius, P. Strohriegl, J. Pielichowski and K. Pielichowski, Prog. Polym. Sci., 2003, 28, 1297.

2 P. Sigwalt, G. Wegner, J.-F. Morin, M. Leclerc, D. Ades and A. Siove, Macromol. Rapid Commun., 2005, 26, 761.

3 N. Blouin and M. Leclerc, Acc. Chem. Res., 2008, 41, 1110.

4 P.-L. T. Boudreault, N. Blouin and M. Leclerc, Adv. Polym. Sci., 2008, 212, 99.

5 S. Beaupre, P.-L. T. Boudreault and M. Leclerc, Adv. Mater., 2010, 22, E6.

6 P.-L. T. Boudreault, S. Beaupre and M. Leclerc, Polym. Chem., 2010, 1, 127.

7 J. Li and A. C. Grimsdale, Chem. Soc. Rev., 2010, 39, 2399.

8 F. Dumur, Org. Electron., 2015, 25, 345.

9 X. T. Tao, Y. D. Zhang, T. Wada, H. Sasabe, H. Suzuki,

T. Watanabe and S. Miyata, Adv. Mater., 1998, 10, 226.

10 J.-F. Morin and M. Leclerc, Macromolecules, 2001, 34, 4680.
11 F. Dierschke, A. C. Grimsdale and K. Müllen, Synthesis, 2003, 2470.

12 T. Mori, T. Shinnai and M. Kijima, Polym. Chem., 2011, 2, 2830 .

13 N. Blouin, A. Michaud and M. Leclerc, Adv. Mater., 2007, 19, 2295.

14 N. Blouin, A. Michaud, D. Gendron, S. Wakim, E. Blair, R. Neagu-Plesu, M. Belletete, G. Durocher, Y. Tao and M. Leclerc, J. Am. Chem. Soc., 2008, 130, 732.

15 R. B. Aich, N. Blouin, A. Bouchard and M. Leclerc, Chem. Mater., 2009, 21, 751.

16 S. Beaupre, A.-C. Breton, J. Dumas and M. Leclerc, Chem. Mater., 2009, 21, 1504.

17 Y. Zou, D. Gendron, R. Badrou-Aich, A. Najari, Y. Tao and M. Leclerc, Macromolecules, 2009, 42, 2891.

18 S. G. Hahm, T. J. Lee, D. M. Kim, W. Kwon, Y.-G. Ko, T. Michinobu and M. Ree, J. Phys. Chem. C, 2011, 115, 21954.

19 T. Umeyama, Y. Watanabe, E. Douvogianni and H. Imahori, J. Phys. Chem. C, 2013, 117, 21148.

20 T. Michinobu, H. Osako and K. Shigehara, Macromol. Rapid Commun., 2008, 29, 111.

21 T. Michinobu, H. Osako and K. Shigehara, Macromolecules, 2009, 42, 8172.

22 S. Habuchi, H. Fujita, T. Michinobu and M. Vacha, J. Phys. Chem. B, 2011, 115, 14404.

23 T. Michinobu, H. Osako, C. Seo, K. Murata, T. Mori and K. Shigehara, Polymer, 2011, 52, 5756.

24 H. Fujita and T. Michinobu, Macromol. Chem. Phys., 2012, 213, 447.

25 A. Facchetti, L. Vaccaro and A. Marrocchi, Angew. Chem., Int. Ed., 2012, 51, 3520.

26 L. G. Mercier and M. Leclerc, Acc. Chem. Res., 2013, 46, 1597.

27 S. Kowalski, S. Allard, K. Zilberberg, T. Riedl and U. Scherf, Prog. Polym. Sci., 2013, 38, 1805.

28 H. Zhao, C.-Y. Liu, S.-C. Luo, B. Zhu, T.-H. Wang, H.-F. Hsu and H.-H. Yu, Macromolecules, 2012, 45, 7783.

29 K. Yamazaki, J. Kuwabara and T. Kanbara, Macromol. Rapid Commun., 2013, 34, 69.

30 J. Kuwabara, T. Yasuda, S. J. Choi, W. Lu, K. Yamazaki, S. Kagaya, L. Han and T. Kanbara, Adv. Funct. Mater., 2014, 24, 3226.

31 Y. Nohara, J. Kuwabara, T. Yasuda, L. Han and T. Kanbara, J. Polym. Sci., Part A: Polym. Chem., 2014, 52, 1401.

32 F. Grenier, B. R. Aich, Y.-Y. Lai, M. Guerette, A. B. Holmes, Y. Tao, W. W. H. Wong and M. Leclerc, Chem. Mater., 2015, 27, 2137.

33 Y. Fujinami, J. Kuwabara, W. Lu, H. Hayashi and T. Kanbara, ACS Macro Lett., 2012, 1, 67.

34 S. J. Choi, J. Kuwabara and T. Kanbara, ACS Sustainable Chem. Eng., 2013, 1, 878.

35 T. N. Glasnov and C. O. Kapper, Macromol. Rapid Commun., 2007, 28, 395.

36 Y. Yuan, T. Michinobu, M. Ashizawa and T. Mori, J. Polym. Sci., Part A: Polym. Chem., 2011, 49, 1013. 
37 M. B. Gawande, S. N. Shelke, R. Zboril and R. S. Varma, Acc. Chem. Res., 2014, 47, 1338.

38 S.-H. Jung, H. K. Kim, S.-H. Kim, Y. H. Kim, S. C. Jeoung and D. Kim, Macromolecules, 2000, 33, 9277.

39 J. Kuwabara, K. Yamazaki, T. Yamagata, W. Tsuchida and T. Kanbara, Polym. Chem., 2015, 6, 891.

40 M. Wakioka, N. Ichihara, Y. Kitano and F. Ozawa, Macromolecules, 2014, 47, 626.

41 J. Kuwabara, Y. Nohara, S. J. Choi, Y. Fujinami, W. Lu, K. Yoshimura, J. Oguma, K. Suenobu and T. Kanbara, Polym. Chem., 2013, 4, 947.

42 J.-H. Chu, C.-C. Wu, D.-H. Chang, Y.-M. Lee and M.-J. Wu, Organometallics, 2013, 32, 272.

43 H. Fujita and T. Michinobu, Heterocycles, 2014, 89, 2346.

44 G. A. Sotzing, J. L. Reddinger, A. R. Katritzky, J. Soloducho, R. Musgrave, J. R. Reynolds and P. J. Steel, Chem. Mater., 1997, 9, 1578.

45 D. Witker and J. R. Reynolds, Macromolecules, 2005, 38, 7636.
46 P. Taranekar, T. Fulghum, A. Baba, D. Patton and R. Advincula, Langmuir, 2007, 23, 908.

47 R. Ponnapati, M. J. Felipe, V. Muthalagu, K. Puno, B. Wolff and R. Advincula, ACS Appl. Mater. Interfaces, 2012, 4, 1211.

48 N. Kobayashi, K. Teshima and R. Hirohashi, J. Mater. Chem., 1998, 8, 497.

49 P. M. Beaujuge and J. R. Reynolds, Chem. Rev., 2010, 110, 268.

50 P. M. Beaujuge, C. M. Amb and J. R. Reynolds, Acc. Chem. Res., 2010, 43, 1396.

51 H.-J. Yen and G.-S. Liou, Polym. Chem., 2012, 3, 255.

52 H.-J. Yen and G.-S. Liou, Chem. Commun., 2013, 49, 9797.

53 J.-H. Wu and G.-S. Liou, Adv. Funct. Mater., 2014, 24, 6422.

54 D. Chao, S. Wang, B. T. Tuten, J. P. Cole and E. B. Berda, Macromolecules, 2015, 48, 5054.

55 X. Ma, H. Niu, H. Wen, S. Wang, Y. Lian, X. Jiang, C. Wang, X. Bai and W. Wang, J. Mater. Chem. C, 2015, 3, 3482. 